\title{
Optimization in an instantaneous economic order quantity (EOQ) model incorporated with promotional effort cost, variable ordering cost and units lost due to deterioration
}

\section{Pattnaik*}

Department of Business Administration, Utkal University, Bhubaneswar, India

\section{H R O N I C L E}

Article history:

Received January 12, 2013

Received in revised format

10 May 2013

Accepted June 192013

Available online

June 252013

Keywords:

$E O Q$

Deterioration

Units lost

Promotional effort cost

Variable ordering cost

\section{A B S T R A C T}

\begin{abstract}
This paper investigates the instantaneous economic order quantity model by allocating the percentage of units lost due to deterioration in an on-hand inventory by framing promotional effort cost and variable ordering cost. The objective is to maximize the net profit so as to determine the order quantity, promotional effort factor, the cycle length and number of units lost due to deterioration. For any given number of replenishment cycles the existence of a unique optimal replenishment schedule are proved and mathematical model is developed to find some important characteristics for the concavity of the net profit function. Numerical examples are provided to illustrate the results of proposed model, which benefit the retailer and this policy is important, especially for wasting of deteriorating items. Finally, sensitivity analyses of the optimal solution with respect to the major parameters are carried out.
\end{abstract}

(C) 2013 Growing Science Ltd. All rights reserved.

\section{Introduction}

Most of the literature on inventory control and production planning has dealt with the assumption that the demand for a product will continue infinitely in the future either in a deterministic or in a stochastic fashion. This assumption does not always hold true. Inventory management plays a crucial role in businesses since it can help companies reach the goal of ensuring prompt delivery, avoiding shortages, helping sales at competitive prices and so forth. The mathematical modeling of real-world inventory problems necessitates the simplification of assumptions to make the mathematics flexible. However, excessive simplification of assumptions results in mathematical models that do not represent the inventory situation to be analyzed.

Many models have been proposed to deal with a variety of inventory problems. The classical analysis of inventory control considers three costs for holding inventories. These costs are the procurement cost, carrying cost and shortage cost. The classical analysis builds a model of an inventory system and calculates the EOQ which minimize these three costs so that their sum is satisfying minimization

* Corresponding author.

E-mail addresses: monalisha_1977@yahoo.com (M. Pattnaik)

(C) 2013 Growing Science Ltd. All rights reserved. doi: $10.5267 /$ j.uscm.2013.06.005 
criterion. One of the unrealistic assumptions is that items stocked preserve their physical characteristics during their stay in inventory. Items in stock are subject to many possible risks, e.g. damage, spoilage, dryness; vaporization etc., those results decrease of usefulness of the original one and a cost is incurred to account for such risks.

The EOQ inventory control model was introduced in the earliest decades of this century and is still widely accepted by many industries today. Comprehensive reviews of inventory models can be found in literature (e.g. Osteryoung et al., 1986, Pattnaik, 2011; Pattnaik, 2013). In previous deterministic inventory models, many are developed under the assumption that demand is either constant or stock dependent for deteriorated items. Jain and Silver (1994) developed a stochastic dynamic programming model presented for determining the optimal ordering policy for a perishable or potentially obsolete product so as to satisfy known time-varying demand over a specified planning horizon. They assumed a random lifetime perishability, where, at the end of each discrete period, the total remaining inventory either becomes worthless or remains usable for at least the next period. Mishra (2012) explored the inventory model for time dependent holding cost and deterioration with salvage value where shortages are allowed. Gupta and Gerchak (1995) examined the simultaneous selection product durability and order quantity for items that deteriorate over time. Their choice of product durability is modeled as the values of a single design parameter that effects the distribution of the time-to-onset of deterioration (TOD) and analyzed two scenarios; the first considers TOD as a constant and the store manager may choose an appropriate value, while the second assumes that TOD is a random variable.

Goyal and Gunasekaran (1995) considered the effect of different marketing policies, e.g. the price per unit product and the advertisement frequency on the demand of a perishable item. Bose, Goswami and Chaudhuri (1995) considered an economic order quantity (EOQ) inventory model for deteriorating goods developed with a linear, positive trend in demand allowing inventory shortages and backlogging. Bose et al. (1995) and Hariga (1996) investigated the effects of inflation and the time-value of money with the assumption of two inflation rates rather than one, i.e. the internal (company) inflation rate and the external (general economy) inflation rate. Hariga (1994) argued that the analysis of Bose et al. (1995) contained mathematical errors for which he proposed the correct theory for the problem supplied with numerical examples. Pattnaik (2011) explained a single item EOQ model with demand dependent unit cost and variable setup cost. Padmanabhan and Vrat (1995) presented an EOQ inventory model for perishable items with a stock dependent selling rate. They assumed that the selling rate is a function of the current inventory level and the rate of deterioration is taken to be constant. Pattnaik (2012a) explained a non-linear profit-maximization entropic order quantity model for deteriorating items with stock dependent demand rate. Pattnaik (2013a) introduced a fuzzy EOQ model with demand dependent unit cost and varied setup cost under limited storage capacity.

The most recent work found in the literature is that of Hariga (1995) who extended his earlier work by assuming a time-varying demand over a finite planning horizon. Pattnaik (2011) assumes instant deterioration of perishable items with constant demand where discounts are allowed. Pattnaik (2010) presented an entropic order quantity (EnOQ) model under instant deterioration for perishable items with constant demand where discounts are allowed. Salameh et al. (1999) studied an EOQ inventory model in which it assumes that the percentage of on-hand inventory wasted due to deterioration is a key feature of the inventory conditions which govern the item stocked. Pattnaik (2012a) discussed an entropic order quantity (EnOQ) model under cash discounts. Pattnaik (2012b) introduced an EOQ model for perishable items with constant demand and instant deterioration. Pattnaik (2012c) studied the effect of promotion in fuzzy optimal replenishment model with units lost due to deterioration. Pattnaik (2013b) investigated linear programming problems in fuzzy environment with evaluating the post optimal analyses. Pattnaik (2013c) discussed wasting of percentage on-hand inventory of an instantaneous economic order quantity model due to deterioration. Raafat (1991) explained survey of 
literature on continuously deteriorating inventory models. Roy and Maiti (1997) presented fuzzy EOQ model with demand dependent unit cost under limited storage capacity. Tripathy et al. (2012) introduced optimal EOQ model for Deteriorating Items with Promotional Effort Cost. Tripathy et al. (2013) presented a decision-making framework for a single item EOQ model with two constraints. Tsao and Sheen (2008) explored dynamic pricing, promotion and replenishment policies for a deteriorating item under permissible delay in payment. Waters (1994) and Pattnaik (2012d) defined various inventory models with managerial decisions. Wee (1993) explained an economic production lot size model for deteriorating items with partial back-ordering. In this paper, replenishment decision under wasting the percentage of on-hand inventory due to deterioration are adjusted arbitrarily upward or downward for profit maximization model in response to the change in market demand within the finite planning horizon with dynamic setup cost with promotional effort cost. The objective of this paper is to determine optimal replenishment quantities in an instantaneous replenishment profit maximization model.

All mentioned above inventory literatures with deterioration or no wasting the percentage of on-hand inventory due to deterioration have the basic assumption that the retailer owns a storage room with optimal order quantity. In recent years, companies have started to recognize that a tradeoff exists between product varieties in terms of quality of the product for running in the market smoothly. In the absence of a proper quantitative model to measure the effect of product quality of the product, these companies have mainly relied on qualitative judgment. This paper postulates that measuring the behavior of production systems may be achievable by incorporating the idea of retailer in making optimum decision on replenishment with wasting the percentage of on-hand inventory due to deterioration with dynamic ordering cost and then compares the optimal results with no wasting the percentage of on-hand inventory with promotional effort cost due to deterioration traditional model. The major assumptions used in the above research articles are summarized in Table1.

Table 1

Summary of the Related Researches

\begin{tabular}{|c|c|c|c|c|c|c|c|c|}
\hline $\begin{array}{l}\text { Author(s) and } \\
\text { published Year }\end{array}$ & $\begin{array}{c}\text { Structure of } \\
\text { the model }\end{array}$ & Demand & $\begin{array}{l}\text { Demand } \\
\text { patterns }\end{array}$ & $\begin{array}{c}\text { Promotional } \\
\text { effort cost }\end{array}$ & $\begin{array}{c}\text { Ordering } \\
\text { Cost }\end{array}$ & Planning & $\begin{array}{l}\text { Units Lost due } \\
\text { Deterioration }\end{array}$ & Model \\
\hline "Hariga (1994)" & $\begin{array}{c}\text { Crisp } \\
\text { (EOQ) }\end{array}$ & Time & $\begin{array}{c}\text { Non- } \\
\text { stationary }\end{array}$ & No & Constant & Finite & No & Cost \\
\hline $\begin{array}{l}\text { "Tsao et al. } \\
\text { (2008)" }\end{array}$ & $\begin{array}{l}\text { Crisp } \\
\text { (EOQ) }\end{array}$ & Time and Price & $\begin{array}{l}\text { Linear and } \\
\text { Decreasing }\end{array}$ & No & Constant & Finite & No & Profit \\
\hline $\begin{array}{l}\text { "Pattnaik } \\
\text { (2010)" }\end{array}$ & $\begin{array}{c}\text { Crisp } \\
\text { (EnOQ) }\end{array}$ & $\begin{array}{c}\text { Constant } \\
\text { (Deterministic) }\end{array}$ & Constant & No & Constant & Finite & No & Profit \\
\hline $\begin{array}{l}\text { "Pattnaik } \\
\text { (2011)" }\end{array}$ & $\begin{array}{l}\text { Crisp } \\
\text { (EOQ) }\end{array}$ & $\begin{array}{c}\text { Constant } \\
\text { (Deterministic) }\end{array}$ & Constant & No & Constant & Finite & No & Profit \\
\hline $\begin{array}{l}\text { Present Paper } \\
\text { (2013) }\end{array}$ & $\begin{array}{l}\text { Crisp } \\
(\text { EOQ) }\end{array}$ & $\begin{array}{c}\text { Constant } \\
\text { (Deterministic) }\end{array}$ & Constant & Yes & Variable & Finite & Yes & Profit \\
\hline
\end{tabular}

The remainder of the paper is organized as follows. In section 2 assumptions and notations are provided for the development of the model. The mathematical formulation is developed in section 3 . The solution procedure is given in section 4. In section 5, numerical example is presented to illustrate the development of the model. The sensitivity analysis is carried out in section 6 to observe the changes in the optimal solution. Finally section 7 deals with the summary and the concluding remarks.

\section{Notations and Assumptions}

$\mathrm{r} \quad$ Consumption rate

$t_{c} \quad$ Cycle length

$\mathrm{h} \quad$ Holding cost of one unit for one unit of time.

$\mathrm{HC}$ (q) Holding cost per cycle

c Purchasing cost per unit 
$\mathrm{P}_{\mathrm{s}} \quad$ Selling Price per unit

$\alpha \quad$ Percentage of on-hand inventory that is lost due to deterioration

q Order quantity

$K \times\left(q^{\gamma-1}\right) \quad$ Ordering cost per cycle (OC) where, $0<\gamma<1$

$\mathrm{q}^{* *} \quad$ Modified economic ordering / production quantity (EOQ/EPQ)

$q^{*} \quad$ Traditional economic ordering quantity (EOQ)

$\varphi(\mathrm{t}) \quad$ On-hand inventory level at time $\mathrm{t}$

$\rho \quad$ The promotional effort factor per cycle.

$\operatorname{PE}(\rho)$ The promotional effort cost, $\operatorname{PE}(\rho)=\mathrm{K}_{1}(\rho-1)^{2} r^{\alpha_{1}}$ where, $\mathrm{K}_{1}>0$ and $\alpha_{1}$ is a constant. $\pi_{1}(q, \rho)$ Net profit per unit of producing q units per cycle in crisp strategy.

$\pi(\mathrm{q}, \rho)$ Average profit per unit of producing $\mathrm{q}$ units per cycle in crisp strategy.

\section{Mathematical Model}

Denote $\varphi(t)$ as the on-hand inventory level at time $t$. During a change in time from point $t$ to $t+d t$, where $\mathrm{t}+\mathrm{dt}>\mathrm{t}$, the on-hand inventory drops from $\varphi(t)$ to $\varphi(t+d t)$. Then $\varphi(t+d t)$ is given as:

$\varphi(t+d t)=\varphi(t)-r \rho d t-\alpha \varphi(t) d t$

Eq. (1) can be re-written as:

$\frac{\varphi(\mathrm{t}+\mathrm{dt})-\varphi(\mathrm{t})}{d t}=-r \rho-\alpha \varphi(\mathrm{t})$

and $\mathrm{dt} \rightarrow 0$, Eq. (2) reduces to:

$\frac{\mathrm{d} \varphi(\mathrm{t})}{d t}+\alpha \varphi(\mathrm{t})+\mathrm{r} \rho=0$

Eq. (3) is a differential equation, solution is

$\varphi(t)=\frac{-r \rho}{\alpha}+\left(q+\frac{r \rho}{\alpha}\right) \times e^{-\alpha t}$

where $\mathrm{q}$ is the order quantity which is instantaneously replenished at the beginning of each cycle of length $t_{c}$ units of time. The stock is replenished by q units each time these units are totally depleted as a result of outside demand and deterioration. The cycle length, $t_{c}$, is determined by first substituting $t_{c}$ into Eq. (4) and then setting it equal to zero to get:

$\mathrm{t}_{\mathrm{c}}=\frac{1}{\alpha} \ln \left(\frac{\propto \mathrm{q}+\mathrm{r} \rho}{\mathrm{r} \rho}\right)$

Eq. (4) and Eq. (5) are used to develop the mathematical model. It is worthy to mention that as $\alpha$ approaches to zero, $t_{c}$ approaches to $\frac{\mathrm{q}}{\mathrm{r} \rho}$. Then the total number of units lost per cycle, $\mathrm{L}$, is given as:

$L=r \rho\left[\frac{q}{r \rho}-\frac{1}{\alpha} \ln \left(\frac{\alpha q+r \rho}{r \rho}\right)\right]$

The total cost per cycle, TC(q), is the sum of the variable ordering cost and purchasing cost per cycle, $K q^{(\gamma-1)}+c q$, the holding cost per cycle, $\mathrm{HC}(\mathrm{q})$, and the promotional effort cost per cycle, $\operatorname{PE}(\rho)$. $\mathrm{HC}(\mathrm{q})$ is obtained from Eq. (4) as :

$$
\begin{aligned}
H C(q) & =\int_{0}^{t c} h \varphi(t) d t=h \int_{0}^{\frac{1}{\alpha} \ln \left(\frac{\alpha \mathrm{q}+\mathrm{r} \rho}{\mathrm{r} \rho}\right)}\left[-\frac{\mathrm{r} \rho}{\alpha}+\left(\mathrm{q}+\frac{\mathrm{r} \rho}{\alpha}\right) \times \mathrm{e}^{-\alpha \mathrm{t}}\right] d t \\
& =h \times\left[\frac{q}{\alpha}-\frac{r \rho}{\alpha^{2}} \ln \left(\frac{\alpha q+r \rho}{r \rho}\right)\right]
\end{aligned}
$$


$\operatorname{PE}(\rho)=K_{1}(\rho-1)^{2} r^{\alpha_{1}}$

$\mathrm{TC}=\mathrm{OC}+\mathrm{PC}+\mathrm{HC}+\mathrm{PE}$

$\mathrm{TC}(\mathrm{q}, \rho)=K q^{(\gamma-1)}+\mathrm{cq}+h \times\left[\frac{q}{\alpha}-\frac{r \rho}{\alpha^{2}} \ln \left(\frac{\alpha q+r \rho}{r \rho}\right)\right]+K_{1}(\rho-1)^{2} r^{\alpha_{1}}$

The total cost per unit of time, TCU (q, $\rho)$, is given by dividing equation (9) by equation (5) to give:

$$
\begin{aligned}
\operatorname{TCU}(q, \rho) & =\left[K q^{(\gamma-1)}+\mathrm{cq}+h \times\left[\frac{q}{\alpha}-\frac{r \rho}{\alpha^{2}} \ln \left(\frac{\alpha q+r \rho}{r \rho}\right)\right]+K_{1}(\rho-1)^{2} r^{\alpha_{1}}\right] \times\left[\frac{1}{\alpha} \ln \left(\frac{\alpha \mathrm{q}+\mathrm{r} \rho}{\mathrm{r} \rho}\right)\right]^{-1} \\
& =\frac{K q^{(\gamma-1)} \alpha+(c \alpha+h) q}{\ln \left(1+\frac{\alpha q}{r \rho}\right)}-\frac{h r \rho}{\alpha}+\frac{K_{1} \alpha(\rho-1)^{2} r^{\alpha 1}}{\ln \left(1+\frac{\alpha q}{r \rho}\right)}
\end{aligned}
$$

As $\alpha$ approaches zero and $\rho=1$ Eq. (10) reduces to TCU (q) $=\frac{K q^{(\gamma-1)} r}{q}+c r+\frac{h q}{2}$ whose solution is given by the traditional EOQ formula, $q^{*}=\left[\frac{h}{2 K r(2-\gamma)}\right]^{1 / \gamma-3}$. The total profit per cycle is $\pi_{1}(q, \rho)$.

$\pi_{1}(\mathrm{q}, \rho)=(\mathrm{q}-\mathrm{L}) \times P_{s}-\mathrm{TC}(\mathrm{q}, \rho)$

$$
=(\mathrm{q}-\mathrm{L}) \times P_{S}-K q^{(\gamma-1)}-\mathrm{cq}-\mathrm{h} \times\left[\frac{q}{\alpha}-\frac{r \rho}{\alpha^{2}} \times \ln \left(\frac{\alpha q+r \rho}{r \rho}\right)\right]-K_{1}(\rho-1)^{2} r^{\alpha 1}
$$

where $\mathrm{L}$, the number of units lost per cycle due to deterioration, and TC $(\mathrm{q}, \rho)$ the total cost per cycle, are calculated from equations (6) and (9), respectively. The average profit $\pi(q, \rho)$ per unit time is obtained by dividing $t_{c}$ in $\pi_{1}(q, \rho)$. Hence the profit maximization problem is

Maximize $\pi_{1}(\mathrm{q}, \rho)$

$\forall \mathrm{q}>0, \rho>0$

\section{Solution Procedure (Optimization)}

The optimal ordering quantity $\mathrm{q}$ and promotional effort $\rho$ per cycle can be determined by differentiating equation (12) with respect to q and $\rho$ separately, setting these to zero. In order to show the uniqueness of the solution in, it is sufficient to show that the net profit function throughout the cycle is jointly concave in terms of ordering quantity q and promotional effort $\rho$. The second partial derivate of equation (12) with respect to q and $\rho$ are strictly negative and the determinant of Hessian matrix is positive. We consider the following propositions.

Proposition 1. The net profit $\pi_{1}(\mathrm{q}, \rho)$ per cycle is concave in $\mathrm{q}$.

Conditions for optimal q

$\frac{\partial \pi_{1}(q, \rho)}{\partial q}=\frac{r \rho}{(\alpha q+r \rho) \alpha}\left(\alpha P_{s}+h\right)-\left(K(\gamma-1) q^{\gamma-2}+c+\frac{h}{\alpha}\right)=0$

The second order partial derivative of the net profit per cycle with respect to q can be expressed as:

$\frac{\partial^{2} \pi_{1}(q, \rho)}{\partial q^{2}}=-\frac{r \rho}{(\alpha q+r \rho)^{2}}\left(P_{s} \alpha+h\right)-\left(K(\gamma-1)(\gamma-2) q^{\gamma-3}\right)$

Since $\operatorname{r} \rho>0,(\gamma-1)(\gamma-2)>0$ and $\left(P_{s} \alpha+h \alpha\right)>0$ Eq. (14) is negative.

Proposition2. The net profit $\pi_{1}(\mathrm{q}, \rho)$ per cycle is concave in $\rho$.

Conditions for optimal $\rho$

$\frac{\partial \pi_{1}(q, \rho)}{\partial \rho}=\left(\frac{1}{\alpha} \ln \left(\frac{\alpha q}{r \rho}+1\right)-\left(\frac{q}{(\alpha q+r \rho)}\right)\right)\left(\frac{r}{\alpha} \times\left(\alpha P_{s}+h\right)\right)-2 K_{1}(\rho-1) r^{\alpha 1}=0$

The second order partial derivative of the net profit per cycle with respect to $\rho$ is 
$\frac{\partial^{2} \pi_{1}(q, \rho)}{\partial \rho^{2}}=-\frac{r q^{2}}{(r \rho+\alpha q)^{2}}\left(\alpha P_{s}+h\right)-2 K_{1} r^{\alpha 1}$

Since $\left(P_{s} \alpha+h \alpha\right)>0, K_{1}>0, \mathrm{r}>0$, it is found that Eq. (16) is negative.

Propositions 1 and 2 show that the second partial derivatives of equation (12) with respect to q and $\rho$ separately are strictly negative. The next step is to check that the determinant of the Hessian matrix is positive, i.e.

$\frac{\partial^{2} \pi_{1}(q, \rho)}{\partial q^{2}} \times \frac{\partial^{2} \pi_{1}(q, \rho)}{\partial q^{2}}-\left(\frac{\partial^{2} \pi_{1}(q, \rho)}{\partial q \partial \rho}\right)^{2}>0$

$\left(\frac{\partial^{2} \pi_{1}(q, \rho)}{\partial q^{2}}\right)$ and $\left(\frac{\partial^{2} \pi_{1}(q, \rho)}{\partial \rho^{2}}\right)$ shown in Eq. (13) and Eq. (15) and

$\frac{\partial^{2} \pi_{1}(q, \rho)}{\partial q \partial \rho}=\frac{\partial^{2} \pi_{1}(q, \rho)}{\partial \rho \partial q}=\frac{r q}{(\alpha q+r \rho)}\left(\alpha P_{S}+h\right)$

The net profit per unit time we have the following maximization problem.

Maximize $\pi_{1}(q, \rho)$

Subject to

$\left[\left(\frac{r\left(\alpha P_{S}+h\right)^{2}}{(r \rho+\alpha q)^{2}}\right)\left[2 K_{1} r^{\alpha_{1}} \rho+K q^{\gamma-1}(\gamma-1)(\gamma-2)+\frac{\rho r q^{2}}{(r \rho+\alpha q)^{2}}-r q^{2}\right]+2 K_{1} r^{\alpha_{1}} K(\gamma-1)(\gamma-2) q^{(\gamma-3)}\right]>0$

$\forall \mathrm{q}, \rho \geq 0$

The objective is to determine the optimal values of $q$ and $\rho$ to maximize the net profit function. It is very difficult to derive the optimal values of $\mathrm{q}$ and $\rho$, hence unit profit function. There are several methods to cope with constraints optimization problem numerically. But here we use LINGO 13.0 software to derive the optimal values of the decision variables.

\section{Numerical Example}

Consider an inventory situation where $\mathrm{K}$ is Rs. 200 per order, $\mathrm{h}$ is Rs. 5 per unit per unit of time, $\mathrm{r}$ is 1200 units per unit of time, $\mathrm{c}$ is Rs. 100 per unit, the selling price per unit $\mathrm{P}_{\mathrm{s}}$ is Rs. $125, \gamma$ is 0.5 and $\alpha$ is $5 \%, K_{1}=2.0$ and $\alpha_{1}=1.0$. The optimal solution that maximizes equation (12) and $q^{* *}$ and $\rho^{*}$ are determined by using LINGO 13.0 version software and the results are tabulated in Table 2 . In the present model the net profit, units lost due to deterioration, the cycle length and order quantity are comparatively more than that of the comparative models, it indicates the present model incorporated with promotional effort cost, variable ordering cost and units lost due to deterioration may draw the better decisions in managerial uncertain space.

Table 2

Optimal values of the proposed model

\begin{tabular}{|c|c|c|c|c|c|c|c|c|c|c|}
\hline Model & Deterioration & Iteration & $q^{* *}$ & $t_{c}^{*}$ & $L^{*}$ & $\mathrm{OC}$ & $\rho^{*}$ & PE Cost & $\pi_{1}(q, \rho)^{*}$ & $\pi(q, \rho)^{*}$ \\
\hline Crisp & Yes & 115 & 25517.82 & 2.355663 & 1473.291 & 1.25201 & 8.5059 & 135213.6 & 171240.2 & 72692.1 \\
\hline Crisp & Yes & - & 220 & 0.183 & 1.002213 & 200 & - & - & 5074.568 & 27806.1 \\
\hline$\%$ Change & - & - & 99.1379 & 92.2315 & 99.9320 & -15874.3 & - & - & 97.03657 & 61.7481 \\
\hline Crisp & No & 41 & 309.839 & 0.258 & - & 200 & - & - & 7345.968 & 28450.8 \\
\hline$\%$ Change & - & - & 98.7858 & 89.0477 & - & -15874.3 & - & - & 95.71014 & 60.8612 \\
\hline
\end{tabular}

\section{Sensitivity Analysis}

It is interesting to investigate the influence of $\alpha$ on retailer behavior. The computational results shown in Table 3 indicates the following managerial phenomena: when the percentage of on hand inventory is lost due to deterioration i. e. $\alpha$ increases, the replenishment cycle length decreases, but the optimal 
replenishment quantity, the optimal total number of units lost per cycle and the optimal promotional effort, the optimal promotional effort cost and optimal total profit per unit of unit time and the optimal average profit per unit of unit time are decreasing and then increasing respectively. The optimal variable ordering cost increases then decreases with increase in $\alpha$. Fig. 1 represents the relationship between the order quantity q and dynamic setup cost OC. Fig. 2 shows the relationship between the order quantity q and units lost per cycle due to deterioration L and Fig. 3 represents the three dimensional mesh plot of units lost per cycle due to deterioration L, order quantity $q$ and net profit per cycle $\pi_{1}$.

Table 3

Sensitivity Analysis of $\alpha$

\begin{tabular}{|c|c|c|c|c|c|c|c|c|c|c|}
\hline$\alpha \%$ & Iteration & $q^{* *}$ & $t_{c}^{*}$ & $L^{*}$ & $\rho^{*}$ & OC & PE Cost & $\pi_{1}(q, \rho)^{*}$ & $\pi(q, \rho)^{*}$ & $\begin{array}{c}\% \text { Change in } \\
\pi_{1}(q, \rho)^{*}\end{array}$ \\
\hline .04 & 107 & 31252.75 & 2.634015 & 1617.499 & 9.375818 & 1.131321 & 168370.4 & 208572.6 & 79184.30 & -21.8012 \\
\hline .10 & 94 & 11881.95 & 1.541512 & 892.2890 & 5.940955 & 1.834789 & 58591.28 & 82305.11 & 53392.45 & 51.93587 \\
\hline .15 & 111 & 7024.196 & 1.145677 & 586.2808 & 4.682760 & 2.386336 & 32550.53 & 50224.19 & 43838.01 & 70.67033 \\
\hline .30 & 74 & 857.3087 & 0.6473005 & 80.54807 & 1.0000 & 6.830640 & 0.0000 & 10014.91 & 15471.81 & 94.15154 \\
\hline .50 & 123 & 1267.706 & 0.4096291 & 125.3938 & 2.323875 & 5.617211 & 4206.346 & 10552.52 & 25761.15 & 93.83759 \\
\hline .90 & 70 & 557.4794 & 0.2362594 & 57.17051 & 1.764688 & 8.470628 & 1403.395 & 5061.191 & 21422.18 & 97.04439 \\
\hline
\end{tabular}

It is interesting to investigate the influence of the major parameters $\mathrm{K}, \mathrm{h}, \mathrm{r}, \mathrm{c}, P_{s}, \gamma, K_{1}$ and $\alpha_{1}$ on retailer's behaviour. The computational results shown in Table 4 indicate the following managerial phenomena:

- $t_{c}$ the replenishment cycle length, $\mathrm{q}$ the optimal replenishment quantity, $\rho$ the optimal promotional effort factor, $\mathrm{L}$ the optimal units lost due to deterioration, PE promotional effort cost, $\pi_{1}$ the optimal net profit per unit per cycle and $\pi$ the optimal average profit per unit per cycle are insensitive to the parameter $\mathrm{K}$ but $\mathrm{OC}$ variable setup cost is moderately sensitive to the parameter $\mathrm{K}$.

- $t_{c}$ the replenishment cycle length, q the optimal replenishment quantity, $\rho$ the optimal promotional effort factor, $\mathrm{L}$ the optimal units lost due to deterioration, PE promotional effort cost, $\pi_{1}$ the optimal net profit per unit per cycle and $\pi$ the optimal average profit per unit per cycle are sensitive to the parameter $h$ but $O C$ variable setup cost is moderately sensitive to the parameter $h$.

- $t_{c}$ the replenishment cycle length and $\rho$ the optimal promotional effort factor are insensitive to the parameter $r$ but $q$ the optimal replenishment quantity, L the optimal units lost due to deterioration, PE promotional effort cost, $\pi_{1}$ the optimal net profit per unit per cycle and $\pi$ the optimal average profit per unit per cycle are sensitive to the parameter $r$ and $\mathrm{OC}$ variable setup cost is moderately sensitive to the parameter $r$.

- $t_{c}$ the replenishment cycle length, $\mathrm{q}$ the optimal replenishment quantity, $\rho$ the optimal promotional effort factor, L the optimal units lost due to deterioration, PE promotional effort cost, OC variable setup cost, $\pi_{1}$ the optimal net profit per unit per cycle and $\pi$ the optimal average profit per unit per cycle are sensitive to the parameter $\mathrm{c}$.

- $t_{c}$ the replenishment cycle length, q the optimal replenishment quantity, $\rho$ the optimal promotional effort factor, L the optimal units lost due to deterioration, PE promotional effort cost, OC variable setup cost, $\pi_{1}$ the optimal net profit per unit per cycle and $\pi$ the optimal average profit per unit per cycle are sensitive to the parameter $P_{s}$.

- $t_{c}$ the replenishment cycle length and $\rho$ the optimal promotional effort factor, $\mathrm{q}$ the optimal replenishment quantity, L the optimal units lost due to deterioration, PE promotional effort cost, $\pi_{1}$ the optimal net profit per unit per cycle and $\pi$ the optimal average profit per unit per cycle are insensitive to the parameter $\gamma$ and OC variable setup cost is highly sensitive to the parameter $\gamma$.

- $t_{c}$ the replenishment cycle length is insensitive to the parameter $K_{1}$ but $\rho$ the optimal promotional effort factor, $q$ the optimal replenishment quantity, $L$ the optimal units lost due to deterioration, OC variable setup cost, PE promotional effort cost, $\pi_{1}$ the optimal net profit per unit per cycle and $\pi$ the optimal average profit per unit per cycle are sensitive to the parameter $K_{1}$. 
- $t_{c}$ the replenishment cycle length is insensitive to the parameter $\alpha_{1}$ but $\rho$ the optimal promotional effort factor, $q$ the optimal replenishment quantity, $L$ the optimal units lost due to deterioration, OC variable setup cost, PE promotional effort cost, $\pi_{1}$ the optimal net profit per unit per cycle and $\pi$ the optimal average profit per unit per cycle are sensitive with static to the parameter $\alpha_{1}$.

\section{Table 4}

Sensitivity Analyses of the parameters $\mathrm{K}, \mathrm{h}, \mathrm{r}, \mathrm{c}, P_{s}, \gamma, K_{1}$ and $\alpha_{1}$

\begin{tabular}{|c|c|c|c|c|c|c|c|c|c|c|}
\hline Parameter & Value & Iteration & $t^{*}$ & $q^{*}$ & $\rho^{*}$ & $L^{*}$ & $\mathrm{OC}$ & PE & $\pi_{1}$ & $\pi$ \\
\hline \multirow{3}{*}{$\mathrm{K}$} & 150 & 84 & 2.355663 & 25517.80 & 8.505927 & 1473.290 & 0.9390087 & 135213.4 & 171240.5 & 72693.13 \\
\hline & 250 & 103 & 2.355664 & 25517.84 & 8.505934 & 1473.292 & 1.565013 & 135213.7 & 171239.9 & 72692.82 \\
\hline & 500 & 159 & 2.355667 & 25517.93 & 8.505953 & 1473.300 & 3.130021 & 135214.4 & 171238.3 & 72692.07 \\
\hline \multirow{3}{*}{$\mathrm{h}$} & 3 & 105 & 2.903642 & 38600.16 & 10.29337 & 2734.249 & 1.017971 & 207280.1 & 251886.8 & 86748.56 \\
\hline & 8 & 109 & 1.836155 & 15751.84 & 6.825782 & 712.0081 & 1.593545 & 81455.37 & 109416.7 & 59590.14 \\
\hline & 10 & 108 & 1.600859 & 12138.90 & 6.069431 & 479.3364 & 1.815266 & 61677.92 & 86008.46 & 53726.44 \\
\hline \multirow{3}{*}{$\mathrm{r}$} & 1100 & 103 & 2.355664 & 23391.34 & 8.505933 & 1350.518 & 1.307683 & 123945.9 & 156970.0 & 66635.15 \\
\hline & 1500 & 94 & 2.355662 & 31897.25 & 8.505926 & 1841.612 & 1.119833 & 169016.8 & 214050.7 & 90866.44 \\
\hline & 2000 & 98 & 2.355662 & 42529.63 & 8.505922 & 2455.480 & 0.9698045 & 225355.5 & 285401.4 & 121155.497 \\
\hline \multirow{3}{*}{ c } & 110 & 94 & 1.379877 & 6200.754 & 3.617054 & 211.4474 & 2.539848 & 16437.53 & 28995.57 & 21013.16 \\
\hline & 115 & 87 & 0.9093268 & 2395.045 & 2.145369 & 54.03439 & 4.086704 & 3148.490 & 8640.132 & 9501.679 \\
\hline & 120 & 102 & 0.4499476 & 700.3591 & 1.282576 & 7.848584 & 7.557351 & 191.6384 & 1536.669 & 3415.217 \\
\hline \multirow{3}{*}{$P_{S}$} & 120 & 114 & 1.906210 & 14018.99 & 5.841228 & 657.4676 & 1.689163 & 56249.97 & 79485.33 & 41698.11 \\
\hline & 130 & 150 & 2.795240 & 42214.49 & 11.72624 & 2881.297 & 0.9734177 & 276125.5 & 327610.0 & 117202.8 \\
\hline & 135 & 140 & 3.225364 & 65058.34 & 15.49008 & 5104.981 & 0.7841127 & 503909.7 & 573460.9 & 177797.3 \\
\hline \multirow{3}{*}{$\gamma$} & 0.3 & 119 & 2.355661 & 25517.76 & 8.505918 & 1473.286 & 0.1645282 & 135213.1 & 171241.3 & 72693.5 \\
\hline & 0.7 & 462 & 2.355672 & 25518.08 & 8.505985 & 1473.312 & 9.527426 & 135215.5 & 171231.9 & 72689.19 \\
\hline & 0.9 & 150 & 2.355689 & 25518.60 & 8.506093 & 1473.352 & 72.50105 & 135219.4 & 171168.9 & 72661.93 \\
\hline \multirow{3}{*}{$K_{1}$} & 3 & 80 & 2.355665 & 18011.92 & 6.003961 & 1039.933 & 1.490219 & 90142.64 & 126168.9 & 53559.79 \\
\hline & 5 & 85 & 2.355668 & 12007.20 & 4.002385 & 693.2462 & 1.825195 & 54085.90 & 90111.78 & 38253.17 \\
\hline & 10 & 81 & 2.355676 & 7503.659 & 2.501202 & 433.2319 & 2.308838 & 27043.30 & 63068.69 & 26773.07 \\
\hline \multirow{3}{*}{$\alpha_{1}$} & 2 & 54 & 2.355722 & 3000.082 & 1.00000 & 173.2160 & 3.651434 & 0.000000 & 36024.74 & 15292.44 \\
\hline & 3 & 192 & 2.355722 & 3000.098 & 1.000005 & 173.2172 & 3.651424 & 0.0939074 & 36024.83 & 15292.48 \\
\hline & 4 & 67 & 2.355722 & 3000.082 & 1.00000 & 173.2163 & 3.651434 & 0.00000 & 36024.74 & 15292.44 \\
\hline
\end{tabular}
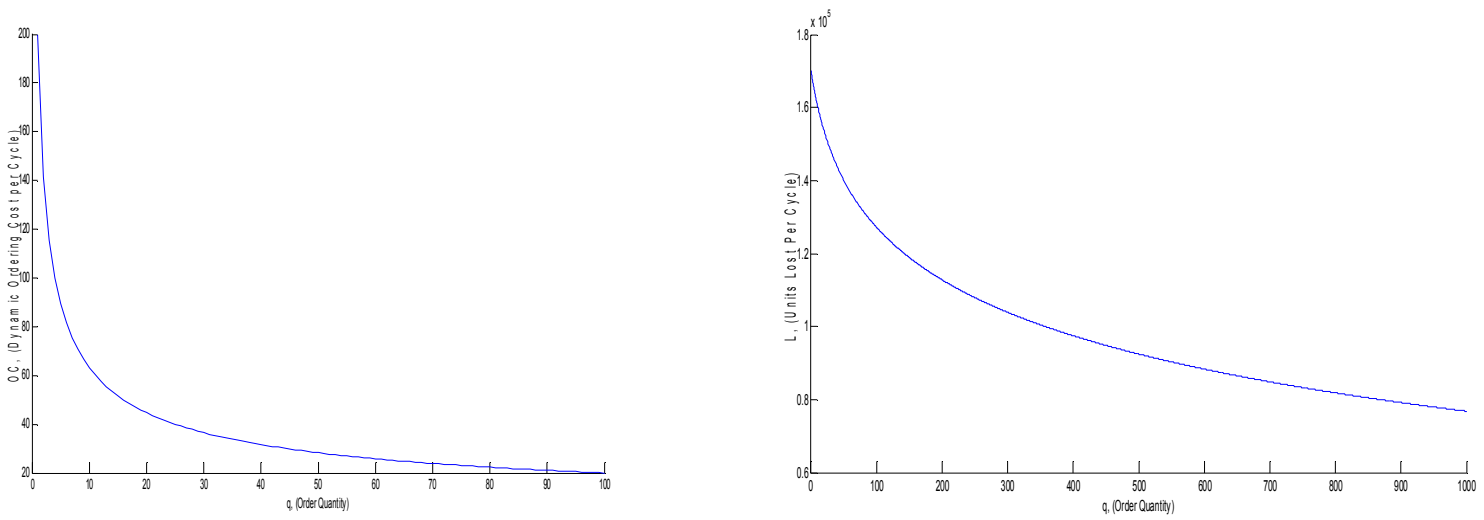

Fig. 1. Two dimensional plot of Order Fig. 2. Two Dimensional Plot of Order Quantity q Quantity, q and Dynamic Ordering Cost, OC and Units Lost per Cycle L

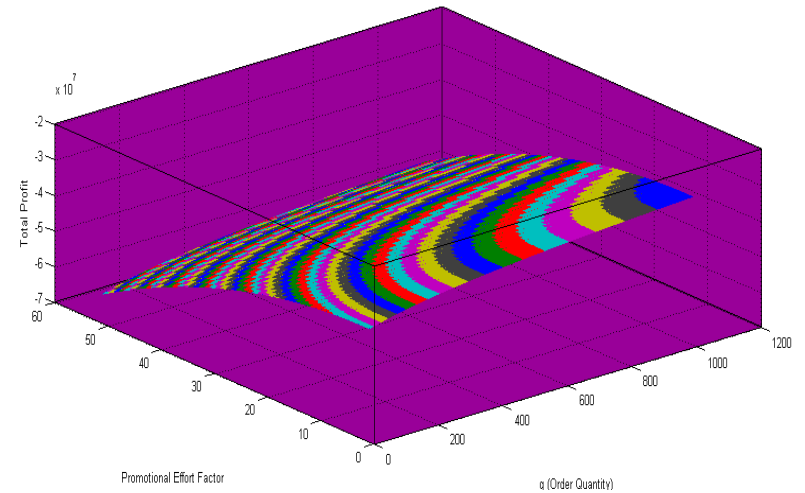

Fig. 3. Three Dimensional Mesh Plot of Order Quantity q, Units Lost per Cycle L and Net Profit per Cycle $\pi_{1}(\rho, q)$ 


\section{Conclusions}

Now a days research on sales promotions has shed much light on the effects of price promotions. Promotional effort factor plays a significant role in framing the promotional effort cost. In this paper, it is analyzed that the effect of promotional effort cost for a modified EOQ model with a percentage of the on-hand inventory lost due to deterioration and variable ordering cost as characteristic features and the inventory conditions govern the item stocked. This paper provides a useful property for finding the optimal profit and ordering quantity with deteriorated units of lost sales. A new mathematical model with variable setup cost is developed and compared to the traditional EOQ model numerically. The economic order quantity, $q^{* *}$ and the net profit for the modified model and the modified average profit per unit per cycle were found to be more than that of the traditional, $q^{*}$, i.e. $q^{* *}>q^{*}$, the net profit and average profit per unit per cycle respectively. Finally, wasting the percentage of on-hand inventory due to deterioration effect was demonstrated numerically to have an adverse effect on the average profit per unit per cycle. Hence the utilization of units lost due to deterioration and promotional effort cost makes the scope of the applications broader. Further, a numerical example is presented to illustrate the theoretical results, and some observations are obtained from sensitivity analysis with respect to the major parameters $\alpha, \mathrm{K}, \mathrm{h}, \mathrm{r}, \mathrm{c}, P_{s}, \gamma, K_{1}$ and $\alpha_{1}$. The model in this study is a general framework that considers wasting/ no wasting the percentage of on-hand inventory due to deterioration with promotional effort cost and variable ordering cost simultaneously. To the best of its knowledge, this is the article that investigates the impact of promotions, units lost due to deterioration and variable ordering cost simultaneously on crisp-type environment.

There are many scopes in extending the present work as a future research work. Parameters and decision variables can be considered random or even fuzzy. Effect of shortage, backlogging inflation etc could be added to the multi-item model.

\section{References}

Bose, S., Goswami, A., \& Chaudhuri, K. S. (1995). An EOQ model for deteriorating items with linear time-dependent demand rate and shortages under inflation and time discounting. Journal of Operational Research Society, 46, 775-782.

Goyal, S. K., \& Gunasekaran, A. (1995). An integrated production-inventory-marketing model for deteriorating items. Computers and Industrial Engineering, 28, 755-762.

Gupta, D., \& Gerchak, Y. (1995). Joint product durability and lot sizing models". European Journal of Operational Research, 84, 371-384.

Hariga, M. (1994). Economic analysis of dynamic inventory models with non-stationary costs and demand. International Journal of Production Economics, 36, 255-266.

Hariga, M. (1995). An EOQ model for deteriorating items with shortages and time-varying demand. Journal of Operational Research Society, 46, 398-404.

Hariga, M. (1996). An EOQ model for deteriorating items with time-varying demand. Journal of Operational Research Society, 47, 1228-1246.

Jain, K., \& Silver, E. (1994). A lot sizing for a product subject to obsolescence or perishability. European Journal of Operational Research, 75, 287-295, 1994.

Mishra, V. K. (2012). Inventory model for time dependent holding cost and deterioration with salvage value and shortages. The Journal of Mathematics and Computer Science, 4(1), 37-47.

Osteryoung, J. S., Mc Carty, D. E., \& Reinhart, W. L. (1986). Use of EOQ models for inventory analysis. Production and Inventory Management, $3^{\text {rd }}$ Qtr., 39-45.

Padmanabhan, G., \& Vrat, P. (1995). EOQ models for perishable items under stock dependent selling rate. European Journal of Operational Research, 86, 281-292. 
Pattnaik, M. (2010). An entropic order quantity (EnOQ) model under instant deterioration of perishable items with price discounts. International Mathematical Forum, 5(52), 2581-2590.

Pattnaik, M. (2011). A note on non linear optimal inventory policy involving instant deterioration of perishable items with price discounts. The Journal of Mathematics and Computer Science, 3(2), 145-155.

Pattnaik, M. (2011). Decision-making for a single item EOQ model with demand-dependent unit cost and dynamic setup cost. The Journal of Mathematics and Computer Science, 3(4), 390-395.

Pattnaik, M. (2011). Entropic order quantity (EnOQ) model under cash discounts. Thailand Statistician Journal, 9(2), 129-141.

Pattnaik, M. (2012a). A note on non linear profit-maximization entropic order quantity (EnOQ) model for deteriorating items with stock dependent demand rate. Operations and Supply Chain Management, 5(2), 97-102.

Pattnaik, M. (2012b). An EOQ model for perishable items with constant demand and instant Deterioration. Decision Science, 39(1), 55-61.

Pattnaik, M. (2012c). Models of Inventory Control. Germany, Lambart Academic Publishing Company.

Pattnaik, M. (2012d). The effect of promotion in fuzzy optimal replenishment model with units lost due to deterioration. International Journal of Management Science and Engineering Management, 7(4), 303-311.

Pattnaik, M. (2013a). Fuzzy NLP for a single item EOQ model with demand - dependent unit price and variable setup cost, waiting for publication. World Journal of Modeling and Simulations.

Pattnaik, M. (2013b). Linear programming problems in fuzzy environment: the post optimal analyses. Journal of Uncertain Systems, in press.

Pattnaik, M. (2013c). Wasting of percentage on-hand inventory of an instantaneous economic order quantity model due to deterioration. The Journal of Mathematics and Computer Science, 7, 154159.

Raafat, F (1991). Survey of literature on continuously deteriorating inventory models. Journal of Operational Research Society, 42, 89-94.

Roy, T. K., \& Maiti, M (1997). A Fuzzy EOQ model with demand dependent unit cost under limited storage capacity. European Journal of Operational Research, 99, 425 - 432.

Salameh, M. K., Jaber, M. Y., \& Noueihed, N. (1993). Effect of deteriorating items on the instantaneous replenishment model. Production Planning and Control, 10(2), 175-180.

Tripathy, P. K., Pattnaik, M., \& Tripathy, P. K. (2012). Optimal EOQ Model for Deteriorating Items with Promotional Effort Cost. American Journal of Operations Research, 2(2), 260-265.

Tripathy, P. K., Pattnaik, M., \& Tripathy, P. K. (2013). A Decision-Making Framework for a Single Item EOQ Model with Two Constraints. Thailand Statistician Journal, 11(1), 67-76.

Tsao, Y. C., \& Sheen, G. J. (2008). Dynamic pricing, promotion and replenishment policies for a deteriorating item under permissible delay in payment. Computers and Operations Research, 35, 3562-3580.

Waters, C. D. J. (1994). Inventory Control and Management. (Chichester: Wiley).

Wee, H. M. (1993). Economic Production lot size model for deteriorating items with partial backordering. Computers and Industrial Engineering, 24, 449-458. 